\title{
Distributed Ledger Technologies, Value Accounting, and the Self Sovereign Identity
}

\author{
Sarah Manski* \\ Department of Global Studies, University of California, Santa Barbara, Santa Barbara, CA, United States
}

Technological activists are designing blockchains and other distributed ledger technologies to challenge extractive value-accounting and identity management in global capitalism. This paper investigates how the new possibilities afforded through distributed ledger technology make possible an alternative future of generative value accounting and self-sovereign identity practices.

Keywords: self-sovereign identity, blockchain, holochain, distributed ledger technology, critical accounting, social movements, sociotechnical imaginary, value

\section{OPEN ACCESS}

Edited by:

Alan Sherriff,

Consultant, United Kingdom

Reviewed by:

Marc Rocas-Royo,

Open University of Catalonia, Spain

Gary Nuttall,

University of Nicosia, Cyprus

*Correspondence:

Sarah Manski

Sarah@Manski.com

Specialty section:

This article was submitted to

Blockchain for Good,

a section of the journal

Frontiers in Blockchain

Received: 29 January 2020

Accepted: 11 May 2020

Published: 23 June 2020

Citation:

Manski S (2020) Distributed Ledger Technologies, Value Accounting, and the Self Sovereign Identity.

Front. Blockchain 3:29.

doi: 10.3389/fbloc.2020.00029
"If power is increasingly leveraged through online and mobile infrastructures-both on the part of movements and on the part of states-then some of the most important (and radical) movements will emerge around the use of those powerful technologies in societies." (Ilten and McInerney, 2019, p. 210).

\section{INTRODUCTION}

The problem with the logic of capitalism is that everything, including healthy social relationships, a stable climate, having meaning in life, etc. are only considered part of the value equation when it impacts profit. Technological activists are rejecting the logic of capitalism and insisting on creating a world where humans and living systems thrive, and therefore are developing new ways to recognize value.

Valuation is a social process, and accounting is a social practice (Callon, 1998; Boltanski and Thévenot, 2006; Callon et al., 2007; Knorr Cetina and Preda, 2012; Aspers and Dodd, 2015). Technological systems have shaped accounting in every setting, including the construction of markets, capital raising, algorithm pricing, digital platform services, and corporate organization. Some of these transformations have been the subjects of intensive study; research on others is lacking. This paper deals with new digital valuation technologies that could transform values and valuations within institutions in which valuation takes place. The same technologies will allow for the reclamation of our digital identities and real reputation, which is necessary for the trust required for online organizing. Technological activists are gaining momentum in their mission to design and use digital technologies for a world beyond capitalism. In this future, people, nature, and things are not valued by the market, but rather by their capacity to further human flourishing and account for planetary limitations. These efforts are part of three contemporary historical determinants recognized by technological activists: first, the need to evade state repression; second, the need to maximize limited resources; and third, the need to create effective institutional solutions despite past failures to do just that.

The construction of each accounting technology is mortared by ideology (Dillard, 1991). The dominant ideology of our age is capitalism. Everyday material technologies of accounting (written 
reports, techniques, books of accounts, pictures, charts) make possible the practice of capitalist governance and corresponding modes of social control. Accounting technologies have material agency within large sociotechnical networks because they enable action at a distance (Robson, 1992), and they make "invisible" objects visible (MacKenzie, 2009). Inscriptions of accounts enable the modern state and institutions to "govern at a distance" and make present things, ideas, and people in "centers of calculation" (Latour, 1987; Miller, 1990).

“... accounting cannot be independent of its social conditions. Under capitalism, the moving force of accounting lies in political economy-in class contradictions. Accounting is made, in part, by adjustment to the economic needs of the ruling class."

(Catchpowle and Cooper, 1999, p. 712).

Tinker (1985) agrees that under capitalism accounting technology is a "logic for appropriating material production," "a way of rationalizing or explaining away the appropriation of the production of one social class by members of another" as "an intellectual and pragmatic tool in social domination" (p. 100). This understanding of accounting calls on scholars interested in building a world free of economic exploitation to understand how social movements and the technologists involved are creating new technologies of valuation and personal identity reflecting an emancipatory imaginary of the future beyond capitalism.

Dillard argues that a "fundamental change in the underlying economic structure must occur before change can occur in accounting technology" (p. 24), but what if technological activists within social movements can reverse this historical process and strategically radically redesign accounting technology; imbuing new accounting technology with favorable affordances that give it transformative material agency to fundamentally change the economic structure? The strategic design of technology has long been a part of activist repertoires. The use of value accounting to demonstrate exploitation and inequality against capitalist opponents is commonplace. It can be found among trade unionists and socialists (Gallhofer and Haslam, 2003), antisweatshop and fair-trade activists (Bartley and Child, 2014), anticorporate globalization campaigners (Juris, 2007), and others. What is new in this historical moment are the emancipatory affordances of modern digital systems of value accounting and digital identity enabled by distributed ledger technologies or DLTs (i.e., blockchain and holochain).

An outline of this paper follows (see Figure 1). Part 1 describes the sociotechnical imaginary of a commons-oriented global social movement. Part 2 reviews what we know about how value is accounted for in capitalism, introduces a theoretical framework for understanding socio-economic objects within capitalist value accounting compared to commons value accounting, and includes a discussion on the tendency in capitalism toward increasing complexity. Part 3 discusses the affordances of blockchain technology, how we might begin to use the material agency of DLTs to shift the organization of value, and a discussion of self-sovereign identity's role in this process. Part 4 explores the possible futures of value accounting as glimpsed

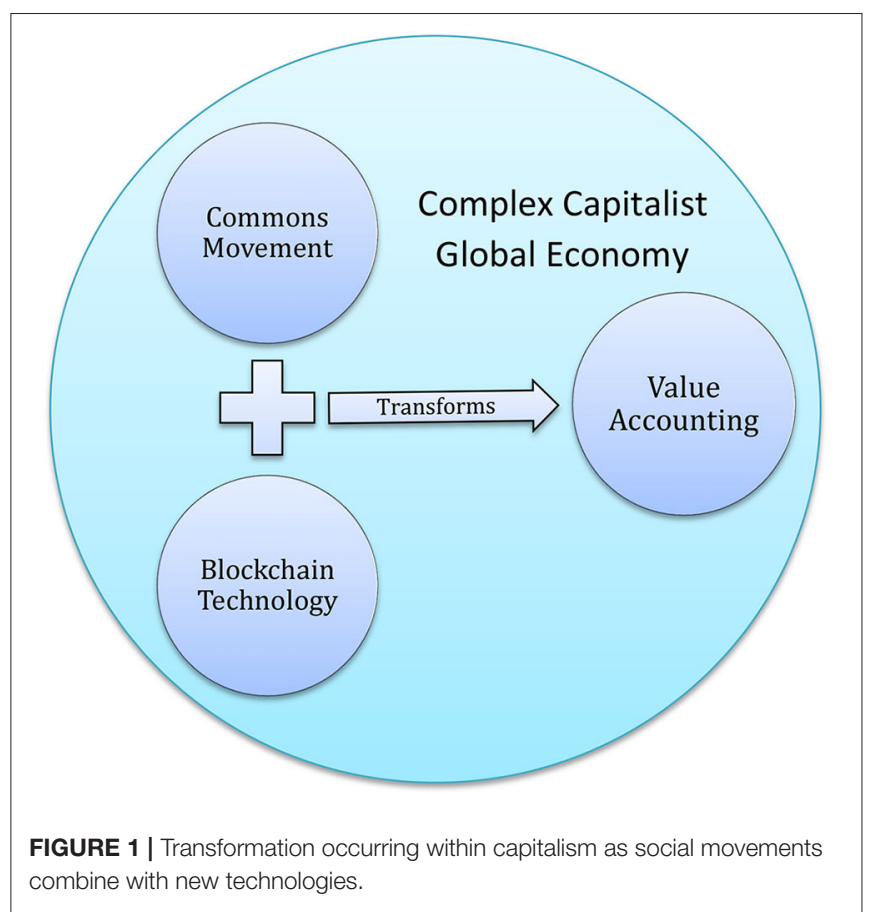

in the MetaCurrency project, Deep Wealth, Holochain, and the distributed application (hApp) Personas. This paper concludes with a vision of the future in which a global movement of entrepreneurs, cooperative members, and technological activists use a new form of value accounting to move beyond capitalism and create the next system for the benefit of all.

\section{PART 1. THE SOCIOTECHNICAL IMAGINARY OF A COMMONS-ORIENTED GLOBAL SOCIAL MOVEMENT}

Globally, hundreds of millions of people are rising and demanding that more than profit be valued (Della Porta et al., 2015). The determination of what is valuable is indicative of how societies can stay together, and what is valued demonstrates our collective social capacity and interdependence upon each other. People create technologies enabling their vision of the future and once created that technology does indeed expand what is possible in the future. Blockchain technology and the post-blockchain DLTs that followed the first Bitcoin blockchain (Nakamoto, 2008) are excellent examples of how sociotechnical imaginaries are put into practice through the design of new technologies.

The question here is, "How do distributed ledger technologies, a new set of technologies that include blockchain and postblockchain systems, shape visions of the future, and how do these visions in turn influence the construction of new technologies?" Several approaches from the futures discourse could be taken to study the social and institutional practice of value accounting. For instance, causal layered analysis (CLA) could be useful for mapping and analyzing a number of competing discourses related to layers of worldview and metaphor (Inayatullah, 1998; 
Inayatullah and Milojevic, 2015), or future empirical research could seek to quantify the multiple dimensions of trust within each technological accounting system and how that impacts user outcomes (Lander and Cooper, 2017). However, the advantage of making use of the concept of the sociotechnical imaginary in this theory paper is that it offers a framework for understanding how a technologist's vision of the ideal future influences their design choices in the present (Jasanoff and Kim, 2009).

Jasanoff and Kim label technologist's utopian vision of the future the "sociotechnical imaginary" (2009). This phrase incorporates the concept of the "sociotechnical" with that of the imaginary. In the field of Science and Technology Studies (STS) the term sociotechnical is used to indicate that technology is neither wholly socially determined nor deriving from an essential internal logic, "Technologies and technical practices are understood as durable (but not immutable) assemblages of social relation and technical artifacts" (Dunbar-Hester, 2019, p. 83). There is a lively discussion among technologists on how to use distributed ledger technology to realize a collective vision of a better future. The findings rely on grounded theory-based interpretations of numerous formal and informal interviews with technologists. Technologists shared an agreement on several standard components of a global technological commonwealth, the movement's emancipatory sociotechnical imaginary (Manski, 2017). This shared imaginary consists of a post-capitalist society where communities of mutual interest cooperate in the construction of institutions of regenerative economic relations. This movement of technologists has a strong faith in serendipity because they believe the necessary pieces will fall together if the correct intentions are directed outward and if the participants are mindful of the opportunities that can be pulled inward. These principles of technological design include:

$\rightarrow$ Technological design should incorporate planetary boundaries

$\rightarrow$ Technological design should be modeled on natural biological ecosystems

$\rightarrow$ Technological design should enable the redefinition of value (ex. Distributed Value Accounting ${ }^{1}$ )

$\rightarrow$ Technological design should enable radically democratic coordination and governance

$\rightarrow$ Technological design should allow for the growth of a cooperative commons as the desirable future.

\section{PART 2. HOW VALUE IS RECOGNIZED UNDER CAPITALISM}

There is a renewal of interest among political economists and others in the role the imagination plays in shaping our vision of the future. Studies of future imaginaries have been conducted in the fields of climate engineering, body enhancement (Roco and Bainbridge, 2002), nanotechnology (Fiedeler et al., 2010), and synthetic biology (Giese et al., 2014). Through the use

\footnotetext{
${ }^{1}$ See Manski, S. G., and Bauwens, M. (2020). Reimagining new socio-technical economics through the application of distributed ledger technologies. Frontiers in Blockchain. 2(29).
}

of our imagination and anticipatory thinking, we can build a bridge from our current present to the desired future present. When we make statements about the desired future, we are making an intervention in the present (Lösch, 2006), because future scenarios, once articulated, influence political debate and policy decisions (Selin, 2007). It is essential to recognize that people engaged in imagining the future bring to this process their ideology, interests, and positions of power within society (Brown et al., 2000). Every network architecture hides a power structure, "we can be a lot more nuanced in the design and usage of technologies by being explicit about the values we imprint in our economic systems" (DisCO.coop, 2019, p. 13). The dominant future imaginary is capitalist, but a commons movement is working on using blockchain technology to transform the nature of capitalist value accounting.

This section briefly reviews the literature on how value is currently accounted for under capitalism, including a discussion on the tendency in capitalism toward increasing complexity. As many researchers have observed, accounting is not neutral nor separate from prevailing economic ideology (Knights and Collinson, 1987; Catchpowle and Smyth, 2016). Critical to capitalism, new accounting and production technologies and organizational forms are invented to increase productivity, reduce the costs of production and manage the resulting processes and complexities (Cooper, 2015), "The only characteristics of concern are those associated with changes in the economic objects." (Dillard, 1991, p. 20).

The logic of capitalism derives from the drive to maximize profit (see Table 2). What is produced is driven by what can be profitably sold on the market, and production decisions are made by the quite small category of people-capitalists-who own and control the means of production. The labor of production is completed by wage laborers who must sell their labor to capitalists to survive, as they receive bank-credit money in return (McCarthy, 2018).

In Capital V1, Marx (2019) states what has value is only that which can be used to produce commodities that can be sold for profit in the market; this form of value is called exchange value. Such a market can only work with the existence of money as a material representation of value. It is the circulation of money as capital, the transformation of nature, and wage labor into commodities that have exchange value that drives capitalist economies. Marx envisioned a mechanization process that we now call modernization by which scientific knowledge and technology come to be more important factors in production. Competition inspires technological and organizational innovations that make value unstable and a "perpetually evolving inner connectivity (an internal or dialectical relation) between value as defined in the realm of circulation in the market and value as constantly being re-defined through revolutions in the realm of production." (Harvey, 2018), "Forces of production and social relations-two different sides of the development of the social individualappear to capital as mere means and are merely means for it to produce on its limited foundation. In fact, however, they are the material conditions to blow this foundation sky-high." (Marx, 1993 [1857-8], p. 705-6). Technological innovations also 
involve greater systemwide complexity, which carries its own challenges in part because defining the concept of complexity is a matter of debate (Pryor, 1996; Rosser, 1999). Hodgson (2003) defines complexity as systemically interconnected and interactive variety within a structured system, "By this definition, increasing economic complexity means a growing diversity of interactions between human beings and between people and their technology." (p. 472).

Early into the study of technology, Mumford (1996) recognized that technologies represent complex layers of objectified intentions that embody cultural artifacts into technical systems. As technological systems change over time, the original design choices gradually solidify and become viewed as timeless. These systems become interlocked and exert power over social systems and intuitions (Hughes, 1987). Our institutions are challenged by increasing complexity, and the digitization of the economy has accelerated this process (DeSanctis and Poole, 1994). The interconnectedness of complex systems makes outcomes more difficult to predict and causes negative consequences (Penow, 1986; Grabowski and Roberts, 1999). Massive amounts of information are available irrespective of geographic boundaries, and increasingly people have access to participation in a formal economy, which is governed by automated algorithmic systems communicating interdependently with each other. Humanity has attempted to solve coordination challenges in complex networks with systems of hierarchy, including monarchies, corporations, militaries, and representative democracies with layers of bureaucracy. Yet, current economic and governance patterns are proving inadequate (Duit and Galaz, 2008). Markets have been proposed as a solution, but current market approaches are proving inadequate, because markets tend to have limited or irregular communication patterns that do not contain information about all that is valued by society such as care work, environmental beauty, leisure time, etc. (Doane, 2002).

Price communicates across complex supply chains incredibly well, but the price of something is an oversimplified communicator of value. For example, when the price of copper goes up, the price of goods that use copper and the price of services that make use of those goods tend to go up as well. At the end of the line, a consumer can sense the difference between a supply chain that makes use of copper and one that makes use of a cheaper alternative because of the difference in sticker price at the point of purchase; the process by which "the invisible hand" functions (Hayek, 1945). However, other forms of information, such as the working conditions under which the copper was mined, or the environmental record of the mining company do not get communicated across the supply chain with nearly the same level of fidelity. This imbalance in the composability of price information vs. other forms of information leads to larger-scale effects that amount to a race to the bottom. The fact that price is the dominant form of information traveling with this level of efficacy is a challenge for technological activists and points toward potential technological solutions.

To overcome this problem, technological activists have asked, is it possible to increase the adaptive capacity of value accounting not just to single organizations but of markets more generally? The conclusion that many have arrived at is that what is needed is more rich and varied forms of information to be not only communicable but also composable. Currently, the use of dollars is the only value metric that is highly composable across contexts (Krafel, 1999; Harris-Braun and Brock, 2018). Activists argue that what is needed are other ways that individuals and communities can communicate about value in ways that can be composed across contexts because whether something is valuable depends on the context.

There is a tension here with the recognition that value judgments are always communicated within specific relationship contexts. And yet, it can be useful to have that information be composable beyond those specific contexts and can also end up altering the dynamic of that initial relationship in the future. For example, there is now pressure for restaurants to create photogenic food that will make a nice picture on Instagram. Matt Schutte, Holochain Director of Communications, argues, "In order to thrive we need to create value accounting systems that increase internal complexity." He is part of a movement of technologists using ideas drawn from the field of cybernetics to explore new technologically enabled protocol cooperativism accounting systems.

Organizational theory states that organized systems must adapt to their environment to survive (Lawrence and Lorsch, 1967; Aldrich, 1979). Ashby's (1961) Law of Requisite Variety, presupposes that "for any system to be stable, the number of states of its control mechanism must be greater than or equal to the number of states in the system being controlled." Activists argue that we need new ways to coordinate in an increasingly complex global system. Technological systems will enable advanced forms of social cooperation that form the principles of a new political economy, a global technological commonwealth. Their socio-technical imaginary of the economy is one in which the primary role of production is to meet the needs of the community; the productive assets are held in common under democratic control; people work because it provides meaning in their lives, and; money is a mutual credit system specific to the community's needs.

\section{PART 3. ACCOUNTING FOR VALUE AND SELF-SOVEREIGN IDENTITY USING DISTRIBUTED LEDGER TECHNOLOGY}

This section explores the social movements of the global technological commonwealth using new technologies strategically to shift value accounting to move beyond capitalism to a commons-based economic system that regenerates both people and the planet. The commons can be managed sustainably by local communities of peers when communities communicate to build standard protocols and rules that ensure their sustainability (Ostrom, 1990). Distributed ledger technologies can be designed for the creation of self-sustaining commons economies where all participants profit according to the value that they produce rather than trying to conform to the capitalist economy. These are the cyber-physical commons powered by blockchain networks, which are designed to align user incentives toward maintaining the system. Miners earn tokens, developers hold the tokens hoping their efforts will raise 
their value, and users purchase tokens creating demand and pay transaction fees.

Open shared ledgers are a key mutual coordination mechanism to shift open-source coordination from software to manufacturing. Blockchain and distributed ledgers generally enable open and contributive ecosystem accounting (such as practiced by SENSORICA (2019), REA (resource-eventagent), which let us see flows in shared circular economies involving multiple players, and biocapacity accounting, which is based on a direct vision of the flows of matter and energy. These types of contributory accounting systems promote fairness, openness, transparency, security, and environmental limits. The current state of the blockchain world is one of fragmentation, but the tools are in development for the creation of interoperable P2P ledgers.

For example, members of the Giveth team are using blockchain technology for good by building a toolkit for creating these new community economies. The project is called the Commons Stack and is a collaboration with BlockScience, a Complex Systems Engineering R\&D firm. The Commons Stack is a project started in 2019 that aims to create community tools to improve decentralized coordination around shared goals. In these "community commons," blockchain technology is used to align economic incentives with each communities's values and scale these previously underfunded communal efforts into effective networks for good. They believe the growth of the commons will be accelerated through access to an open-source library of modular, customizable, and interoperable components enabling purpose-driven communities to unite around shared goals (Figure 2).

(Figure 2. The Commons Stack is building a library of tools for context-specific methods of governance, incentivization, accountability, monitoring, and initialization using holistic system simulations. Used with permission. Graphic by Jeff Emmet, published in "Commons Stack System Overview").

The Commons Stack project has identified components for what they term a "Minimum Viable Commons," to provide essential functionality in coordinating a group around raising and allocating funds, making decisions, and measuring impact. The first component is the "Augmented Bonding Curve," providing continuous funding for a commons initiative through community transvestment, with growing academic foundations for this new economic tool. The second is a transparent and accountable proposal service, which they call the "Giveth Proposal Engine." The third is a novel process for continuous decision making modeled off the mechanics of a neuron firing in the brain, called "Conviction Voting." And, finally, a means to monitor and measure the value produced in these communities, they term the "Commons Analytics Dashboard," which they see leading to a future of Computer Aided Governance. The most important aspect of the Commons Stack is their emphasis on Token Engineering, including the use of an open-source sophisticated system modeling and simulation tool called CAD.

The Commons Stack is using the emerging discipline of token engineering to design technological improvements to streamline community fundraising and decision making, lowering the barriers for groups with shared goals to operate as distributed protocol cooperatives. They are doing this by producing design patterns for community toolkits, a library of code specifications and reference implementations. These designs will be chainagnostic and can be applied to data-centric and/or agentcentric architectures (see Appendix 2). However, most developer interest so far exists in the Ethereum ecosystem, so that is likely where they will see their designs first implemented.

The Commons Stack could be the technological evolution needed to enable the growth of the commons by enabling crypto-economic systems of cooperation and governance. This modular "cultural and technical stack for the commons," could help communities reach shared goals by giving them the tools to bootstrap necessary funding (often the main hindrance to launching), and empowering that community with proportionally weighted peer governance, real-time preference signaling, and monitoring systems that respect complexity. By creating a growing library of open source component blueprints for governance, funding, and other critical infrastructure, the Commons Stack enables communities to act as effective platform cooperatives, co-owning and co-managing shared funds as a commons. These components can be combined to create intentional, circular, community-driven economies powered by continuous funding streams and transparent decision making, which will enable the threefold coordination of the postcapitalist economy.

"In materializing, objectifying, and displaying the value of acts, the publicity and formality of ritual approximate the way the market objectifies the value of work but making the consequences impossible to commoditize. One might even say that ritual decommoditizes value." (Lambek, 2013, p. 154).

In the quote above, Lambek discusses how humans have used ritual to define community value. Ritual returns a sense of the sacred to human activity, while commodification alienates humans from their labor. Technological activists argue to move to a cooperative, post-capitalist planet; then on the societal level, we must decommodify human energies by treating our productive activity as sacred and ethical. Macpherson (1973) argued that human activity is moral when our internal and external motivations for performing acts are in alignment, "Man is not a bundle of appetites seeking satisfaction but a bundle of conscious energies seeking to be exerted" (p. 4-5). To the greatest extent possible, value must be incommensurable; meaning value must remain unique and unalienated.

How could we even begin this process? Technologies have material agency, defined as the structured set of relations enabling or constraining different sets of possibilities. On a global scale, technological activists are designing new technologies with the agency to open new pathways and foreclose others via the operation of technology's "material agency."

Distributed ledger technologies (DLTs), such as blockchains, are contributing to a wave of infrastructure distribution in industrial production. Such distribution is made possible because people place their trust in the software to accurately validate the 


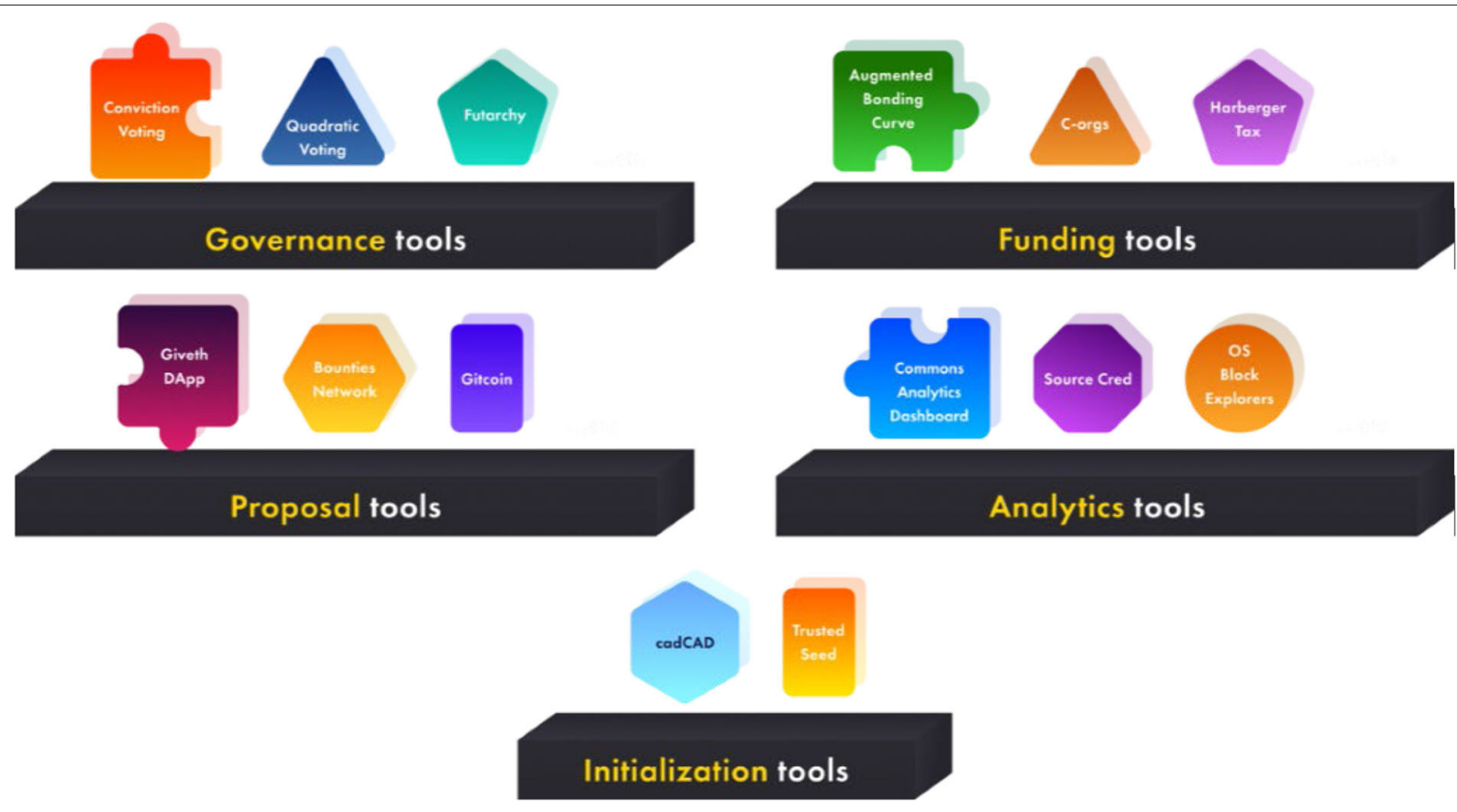

FIGURE 2 | A future stack for the commons (used with permission. Graphic by Jeff Emmet, published in "Architecting the Cyber-Physical Commons", https:// medium.com/commonsstack/architecting-the-cyber-physical-commons-a294d88b5415).

transaction rather than trusting a bank or other intermediary. Some DLTs are being designed to be "unencloseable," meaning that no party can capture and control the communication occurring on the ledger. This is being done so that these DLTs are non-commodifiable in traditional capitalist markets, and in theory, they will enable more democratic forms of governance and organizational structures. Yet these radical possibilities will not be realized without strategic action to design systems that alter value in financial, service, and national infrastructures. Blockchain is an emergent technology created to enable the transfer of value with increased transparency, efficiency, and security (Nakamoto, 2008) that possesses a transformative material agency (Manski, 2017). The affordances of blockchain technology are directly available in its code, and seven such tendencies are listed in Table $\mathbf{1 .}$

(Used with permission. The data from this Table $\mathbf{1}$ are from: "No Gods No Masters No Coders? The Future of Sovereignty in a Blockchain World," by Manski, Sarah Grace, and Manski and Manski (2018), Law and Critique, 29:2, pp 151-162).

The material agency of distributed ledger technology could enable "the construction of self-sovereign identity." The word sovereignty refers to "the receiving of a general recognition of exclusive domain and consequent possession of the capacity to establish the rules of conduct within a particular field of action" (Manski and Manski, 2018). We all have both offline and online identities. For anyone who uses digital systems, tied to our material identity are various digital identities. For the most part, these digital identities are not under our control, and often,
TABLE 1 | Seven tendencies of blockchain technology.

1. Verifiability. Transactions are assured through encrypted network consensus mechanisms in such a form that all transactions from the very first to the most recent are recorded in a ledger open to its maintainers, reducing information asymmetries.

2. Globality. Digital transactions and cultural information flows transcend geographic space and national borders.

3. Liquidity. Value liquidity is enhanced as the location of a store of value that does not depend on or is not under the direct control of a sovereign, central bank, or private corporation.

4. Permanence. The ledger of a transaction is immutable by design.

5. Ethereality. Transactions are conducted in a digital medium.

6. Decentralization. The ledger is widely distributed among many stakeholders and maintainers.

7. Future Focus. Found in newer developments of blockchain such as Ethereum, a stored autonomous self-reinforcing agency (SASRA) is formed in the temporal displacement of action through the use of smart contracts enabling the prefigurative recording of future transactions.

Used with permission. Published in Manski and Manski (2018).

we are not able to see what information is contained within each system. Problematically, if the information is incorrect, we cannot correct these errors, nor do we control what and with whom information is shared and sold. The self-sovereign infrastructure allows users to set boundaries regarding who has access to their data and maintain their privacy. It can also reward users for being contributors. This infrastructure thus will enable people to protect their autonomy while conducting joint work and collective action. 
TABLE 2 | Socio-economic objects within capitalist value accounting compared to commons value accounting.

\begin{tabular}{lll}
\hline $\begin{array}{l}\text { Socio- } \\
\text { economic } \\
\text { objects }\end{array}$ & $\begin{array}{l}\text { Capitalist value } \\
\text { accounting }\end{array}$ & Commons value accounting \\
\hline Human labor & Commodity value & Reflects the species being \\
\hline Time & $\begin{array}{l}\text { Continuous made } \\
\text { discrete }\end{array}$ & $\begin{array}{l}\text { Experienced via natural body } \\
\text { processes }\end{array}$ \\
\hline Institutions & Embodiments of class & $\begin{array}{l}\text { Reflects individuals' perceptions } \\
\text { of themselves }\end{array}$ \\
\hline Transactions & $\begin{array}{l}\text { Restricted to narrow } \\
\text { prespecified attributes }\end{array}$ & $\begin{array}{l}\text { Incorporates a broad range of } \\
\text { social/environment attributes }\end{array}$ \\
\hline $\begin{array}{l}\text { Means of } \\
\text { production }\end{array}$ & Capital dominates labor & Labor dominates capital \\
\hline
\end{tabular}

Our “'technical' technologies will not generate broad human gains unless we invest an equal amount of time, energy, and resources in the development of social and emotional technologies that drive how our whole society is organized and how we work together.” Kaliya Identity Woman (2017) is making the argument any technology controlled by corporations and governments will always restrict human progress. Manski and Manski (2018) support this point by outlining five possible future scenarios of blockchain technology and conclude technology without direct social movement intervention always reinforces existing power relations. They take a contrasting position to those who believe individual self-sovereign identity is the most likely outcome of the use of new technology,

\begin{abstract}
"In blockchain's tendencies toward verifiability, globality, permanence, and future focus, state actors are finding greater capacities to intervene globally in the daily lives of individuals. These expanded capacities are making possible the emergence of new technological totalitarian forms of state sovereignty. To begin with, states cannot easily control what they cannot measure, and a blockchain-enabled Internet of Things (IoT) amplified by artificial intelligence furthers the degree with which states can monitor the material and social world. The rapidly expanding IoT is expected to more than triple in size by 2020 to nearly 21 billion devices (Stavridis and Weinstein, 2016). When there is a tiny blockchain-connected chip embedded in each material object with which we interact, state institutions will assuredly seek to monitor and discipline the personal, political, and economic activities of the many." (Manski and Manski, 2018).
\end{abstract}

\section{PART 4. FUTURE OF VALUE ACCOUNTING: METACURRENCY, DEEP WEALTH, HOLOCHAIN AND PERSONAS}

Holochain is a clear case of a new technology strategically created by social movement activists to achieve regenerative value accounting, which they call "holoptical" knowledge accounting. On New Year's Eve of 2016, Eric Harris-Braun and Arthur Brock started to build Holochain, "For me, what we need to create is a very rich multidimensional accounting. We need lots of feedback loops beyond the single dimension of price." (Brock, 2017). Holochain was created by the founders of the MetaCurrency Project to realize a part of their socio-technical imaginary. Holochain is the foundation for Holo, a cloud hosting market for dApps, and the future of the Internet.

\begin{abstract}
"Holo as a name was not pulled from a hat. It has roots. Back in the original collective intelligence of tribal communities, we had holopticism where everyone participates as part of a feedback loop of the whole. Holomidal instead of pyramidal, where, together, we sensed the whole. This isn't just voting or even decision-making, this is about an embodied integral experience of sensing together. In the original collective intelligence, there is co-creation and connectedness, even in a changing environment. We need less democratic debate in this form because holoptical clarity shapes individual actions. Holopticism doesn't mean you see everything; you see the whole from your perspective. And it, then, collectively becomes aperspectival by our sensing and communicating together." (Russell, 2018)
\end{abstract}

Holochain is a DLT platform-based ecosystem with affordances fostering co-production, open content, and co-ownership. Holochain, aims at facilitating interconnectivity among direct and indirect participants, such as those who install Holochain on their hardware devices to provide hosting space and those who access Holochain through a web browser. One of the advantages of this design is that it avoids the blockchain requirement for global consensus among maintainers and thus affords greater scalability, as well as 'self-sovereignty;' the user controls their data and identity information. The design of holochain is extremely distributed for a $\mathrm{DLT}^{2}$. Holochain activists call this design 'agent-centric' as opposed to corporate 'data-centric' models. The affordances of this design mean that users are given sovereign control over their data and are solely responsible for granting permissions.

Holochain does not have a built-in currency or token. However, the distributed internet architecture Holo does use a cryptocurrency HOT Fuel and Holochain was designed to make it easy to bid alternative cryptocurrencies in the form of distributed accounting applications (dApps). Holo Fuel, a mutual credit system (Manski and Bauwens, 2020), will cover the costs for data storage and Holochain development and maintenance. Holo Fuel is not a crypto-token or cryptocoin, but a mutual credit system issued within a double accounting system where one party holds a debit (the provider of goods and services) and the other party holds a credit (a debt to the provider of goods and services). On Holochain every transaction is countersigned on the local chains of both counterparties. Holo Fuel will be purchased as a token or received as a credit. This process occurs either through the exchange of fiat currency or another cryptocurrency into Holo Fuel or by setting credit limits; Holo Fuel to be paid later. The exchange of money and cryptocurrencies into Holo Fuel and the allocation of credit limits are done through the "Reserve Accounts," which is a facility provided by Harris-Braun and Brock (2018).

${ }^{2}$ For a comparison between Blockchain and Holochain, see Appendix 1. 


\begin{abstract}
"MetaCurrency is the name for the infrastructure and protocols necessary for an open source economy, and free currencies to flow in an interoperable and standardized way" (Harris-Braun, 2018). The open source economy and free currencies are meant to function in a non-monopolizable manner by building protocols and platforms to 'open source' the next economy (Brock, 2009), "Building the core infrastructure for open sourcing money and currencies and developing projects that embody the values of Deep Wealth design." (Harris-Braun et al., 2018).
\end{abstract}

The concept of Deep Wealth (see Figure 3) shifts the value accounting incentive from accumulating material wealth to experiencing wealth through elements such as beautiful surroundings, friendship, capacity of being generous, leisure, travel, family and fun and perhaps, most importantly, deep connections with others (Brock, 2009). In the view of Metacurrency, there are three forms of wealth. The first is tradable wealth: food, time, energy, services, material resources, etc. The second is measurable wealth: performance, sustainability, physiological health, quality, etc. and the third is acknowledgeable wealth: fun, love, care, trust, beauty, etc. Each of these three forms of wealth is a subset of the other. For example, time is tradable wealth as well as measurable and acknowledgeable wealth; together, they create "integral wealth" (The MetaCurrency Project).

Technological activists involved with Metacurrency and Holochain refer to a "quantum leap" transition from a complex capitalist political economy to a post-capitalist society where information technology plays a significant role in fostering the creation of large-scale collective intelligence. The design of Metacurrency's technologies model the same organizational patterns as living systems. By "living systems," these activists refer to biological organisms, atoms, forests, languages and other continuously transforming systems, "the same kind of architectures of intelligence that makes it possible for trillions of cells to work together in an organism." (Harris-Braun and Brock, 2018). Within this architecture, "communication is virtually instantaneous (electronic), peered, decentralized, semantic and designed to evolve in response to rapidly changing needs" (Harris-Braun et al., 2018). Such communication parameters lead to effective, large scale, distributed collaboration that would remove "most of the power structures that underpin the social barriers to change and could make formerly intractable problems (such as climate change, species extinction, resource depletion, or poverty) quite readily solvable." (Harris-Braun et al., 2018).

Blockchains are token-centric, and by this, I mean that they are concerned with the history of token transactions and not necessarily with the people at the end of each transaction. In contrast, the creators of Holochain designed Personas as an agent-centric solution that allows individual users to maintain a reputation. This reputation will document their behavior within a community and across multiple applications that need a person's profile information. In this way, users will be able to trust those with whom they are transacting. Personas allow the user to store and edit their information in one account, similar to "log-in with Google $\mathrm{e}^{3 "}$ and offer/revoke any applications' access to it ${ }^{4}$ In addition, to control your data, Personas is designed to allow users to create multiple identities within each account so that users can have a different business, personal, government, medical, family, and friend personas. Each persona can also have an expiration date. It allows for the revocability of data as required by European Union law ${ }^{5}$.

The definition of value has been changing for the past few decades, from market value to community value, and distributed ledger technologies are furthering this transformation by pushing out centralized identities in favor of self-sovereign identities. The widespread adoption of self-sovereign identity applications, such as Holochain-based Personas, is still yet to be realized, but the incredible interest in user-controlled identity makes it likely that some DLT application will make this a reality. Distributed ledgers are a critical piece of the puzzle of technologies including, smartphones, cloud computing, public key infrastructure (PKI), open standards for decentralized identifiers, directed identifiers, and open standards for verified claims (DIDs) fitting together to enable selfsovereign identities.

\section{CONCLUSION}

This article seeks to begin a dialogue on the topic of how distributed ledger technologies may transform our understanding of value and identity. Valuation is a social process, and distributed organizations of technological activists are utilizing new technologies to disrupt accounting and identity management in contemporary capitalism, and thus transforming global economics, the nature of work, and the distribution of wealth. This paper explores the radical generative accounting practices and ideological imaginaries underpinning this new form of social movement activism, and whether or not the development of new technologies of value accounting and selfsovereign identity may address the challenges of an increasingly complex global political economy of the future.

There is not a straight line between technological innovation and the increasing complexity of the political economy. As a society, we can decide to create technologies that will enrich humanity rather than commodify it. However, it is a certainty that if we continue to live on a planet where capitalism is the dominant determinant of value accounting and social identity, then expanding complexity and distorted value accounting will usher humanity to the edge of the collapse of democratic civilization.

Self-Sovereign Identity is a necessary but insufficient tool to deal with some aspects of growing complexity. Only a widespread popular global movement will have the power to snuff out the underlying drivers of capitalism. As a part of this process, we can use new forms of value accounting to reinforce and reify the social system under which we imagine we want to live. There is a growing movement of social entrepreneurs, cooperatives,

\footnotetext{
${ }^{3}$ Test out Personas' demo here: https://bit.ly/2SfhKIT.

${ }^{4}$ See how PayPall sells your data here: https://rebecca-ricks.com/paypal-data/.

${ }^{5}$ the General Data Protection Regulation 2016/679.
} 


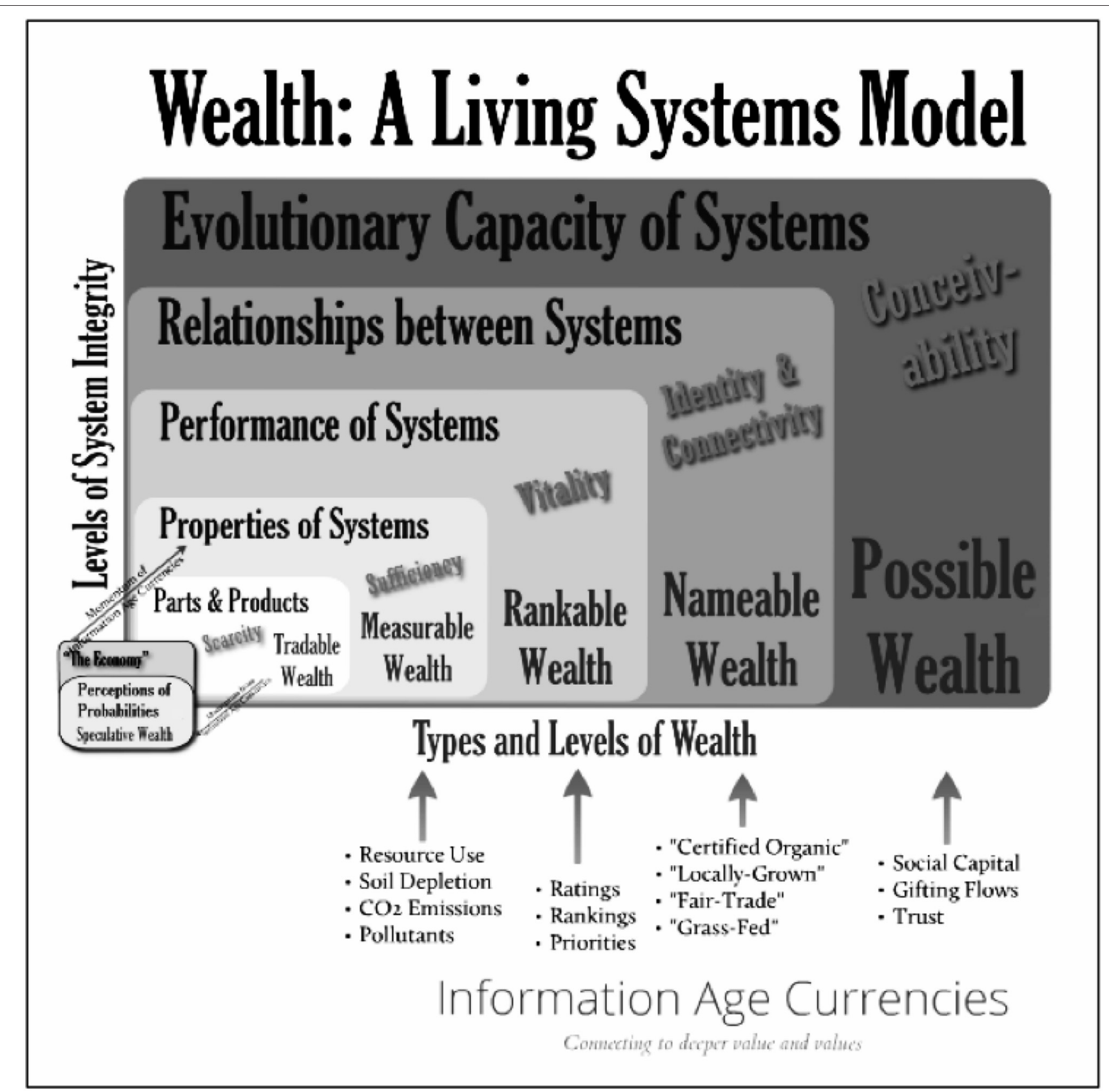

FIGURE 3 | Deep Wealth (used with permission. Graphic by Arthur Brock, published at https://metacurrency.org/portfolio-item/living-systems-model-of-wealth/).

and technological activists who are using these technologies in pursuit of cooperative ownership and management of wealth. It is in everyone's interest to pay attention to this development.

\section{REFERENCES}

Aldrich, H. E. (1979). Organizations and Environments. Englewood Cliffs, NJ: Prentice-Hall.

\section{AUTHOR CONTRIBUTIONS}

The author confirms being the sole contributor of this work and has approved it for publication.

Ashby, W. R. (1961). An Introduction to Cybernetics. London: Chapman and Hall Ltd.

Aspers, P., and Dodd, N. (2015). Re-imagining Economic Sociology. Oxford: Oxford University Press. doi: 10.1093/acprof:oso/9780198748465.001.0001 
Bartley, T., and Child, C. (2014). Shaming the corporation: the social production of targets and the anti-sweatshop movement. Am. Soc. Rev. 79, 653-679. doi: $10.1177 / 0003122414540653$

Boltanski, L., and Thévenot, L. (2006). On Justification. Economies of Worth. Translated by Catherine Porter. Princeton, NY: Princeton University Press.

Brock, A. (2009). New Economy, New Wealth. Retrieved. Available online at: https://prezi.com/xmzld_-wayho/new-economy-new-wealth (accessed August 8, 2019).

Brock, A. (2017). Intro to Currency Design. ArtBrock.com. Available online at: https://www.artbrock.com/2017/02/27/intro-to-currency-design (accessed January 12, 2019).

Brown, J., Rappert, B., and Webster, A. (2000). Contested Futures. A Sociology of Prospective Techno- Science. Burlington, VT: Ashgate.

Callon, M. (1998). The Laws of the Markets. Oxford: Blackwell.

Callon, M., Millo, Y., and Muniesa, F. (2007). Market Devices. Oxford: Blackwell.

Catchpowle, L., and Cooper, C. (1999). No escaping the financial: the economic referent in South Africa. Crit. Perspect. Account. 10, 711-746. doi: 10.1006/cpac.1998.0257

Catchpowle, L., and Smyth, S. (2016). Accounting and social movements: an exploration of critical accounting praxis. Account. Forum 40, 220-234. doi: 10.1016/j.accfor.2016.05.001

Cooper, C. (2015). Accounting for the fictitious: a Marxist contribution to understanding accounting's roles in the financial crisis. Crit. Perspect. Account. 30, 63-82. doi: 10.1016/j.cpa.2014.08.002

Della Porta, D., Andretta, M., Calle, A., Combes, H., Eggert, N., Giugni, M. G., et al. (2015). Global Justice Movement: Cross-National and Transnational Perspectives. London: Routledge.

DeSanctis, G., and Poole, M. S. (1994). Capturing the complexity in advanced technology use: adaptive structuration theory. Organ. Sci. 5, 121-147. doi: $10.1287 /$ orsc.5.2.121

Dillard, J. (1991). Accounting as a critical social science. Account. Audit. Accountability J. 4, 8-28. doi: 10.1108/09513579110143849

DisCO.coop (2019). If I Only Had a Heart: A DisCO Manifesto. Available online: https://disco.coop/wp-content/uploads/2019/11/DisCO_Manifesto-v1-1.pdf (accessed April 1, 2020).

Doane, D. (2002). Market Failure: the Case for Mandatory Social and Environmental Reporting. London: New Economics Foundation.

Duit, A., and Galaz, V. (2008). Governance and complexityemerging issues for governance theory. Governance 21, 311-335. doi: 10.1111/j.1468-0491.2008.00402.x

Dunbar-Hester, C. (2019). "If "Diversity" Is the answer, what is the question? Understanding diversity advocacy in voluntaristic technology projects," in digitalSTS: A Field Guide for Science \& Technology Studies 81.

Fiedeler, U., Coenen, C., Davies, S.R., and Ferrari, A. (2010). Understanding Nanotechnology: Philosophy, Policy and Publics. Heidelberg: AKA.

Gallhofer, S., and Haslam, J. (2003). Accounting and Emancipation: Some Critical Interventions. London: Routledge. doi: 10.4324/9780203986622

Giese, B., Pade, C., Wigger, H., and von Gleich, A. (2014). Synthetic Biology: Character and Impact. Heidelberg: Springer. doi: 10.1007/978-3-319-02783-8

Grabowski, M. and Roberts, K. H. (1999). Risk mitigation in virtual organizations. Organ. Sci. 10, 704-721. doi: 10.1287/orsc.10.6.704

Harris-Braun, E. (2018). Metacurrency Project - P2P Foundation. Available online at: http://wiki.p2pfoundation.net/Metacurrency_Project (accessed August 14th, 2019).

Harris-Braun, E., and Brock, A. (2018). Grammatic Capacities and the Evolution of Complex Adaptive Systems. Available online at: https://docs.google.com/ document/d/12Jd7ZeUzT-k6h2Qxw9jmOhNVlkYD1RnO4t2_mp6g4kg/edit (accessed August 14, 2019).

Harris-Braun, W., Luck, N., Perrin, N., Russell, J., McGuire, E., Harris-Braun, E., et al. (2018). Holo Green Paper. Available online at: https://files.holo.host/2018/ 03/Holo-Green-Paper.pdf (August 8, 2019).

Harvey, D. (2018). Marx's Refusal of the Labour Theory of Value. Retrieved from http://davidharvey.org/wp-content/uploads/2018/03/MARX\%E2\%80\%99S_ REFUSAL_OF_THE_LTV.pdf

Hayek, F. A. (1945). The use of knowledge in society. Am. Econ. Rev. 35, 519-530.

Hodgson, G. (2003). Capitalism, complexity, and inequality. J. Econ. Issues 37, 471-478. doi: 10.1080/00213624.2003.11506595
Hughes, T. P. (1987). “The evolution of large technological systems," in The Social Construction of Technological Systems, eds W. E. Bijker, T. P. Hughes, and T. Pinch (Cambridge, Ma: The MIT Press), 51-82.

Ilten, C., and McInerney, P. B. (2019). "Social movements and digital technology a research Agenda," in digitalSTS: A Field Guide for Science and Technology Studies (Princeton, NJ: Princeton University Press), 198. doi: $10.2307 / j . c t v c 77 \mathrm{mp} 9.18$

Inayatullah, S. (1998). Causal layered analysis: poststructuralism as method. Futures 30, 815-829. doi: 10.1016/S0016-3287(98)00086-X

Inayatullah, S., and Milojevic, I. (2015). CLA 2.0: Transformative Research in Theory and Practice Tamsui: Tamkang University Press.

Jasanoff, S., and Kim, S. H. (2009). Containing the atom: Sociotechnical imaginaries and nuclear power in the United States and South Korea. Minerva 47:119. doi: 10.1007/s11024-009-9124-4

Juris, J. S. (2007). "Practicing militant ethnography with the movement for global resistance in Barcelona," in Constituent imagination: Militant Investigations, Collective Theorization (Chico, CA: AK Press), 11-34.

Kaliya Identity Woman. (2017). Humanizing Technology. openDemocracy. Available online at: https://www.opendemocracy.net/en/transformation/ humanizing-technology/ (accessed March 23, 2019).

Knights, D., and Collinson, D. (1987). Disciplining the shopfloor: a comparison of the disciplinary effects of managerial psychology and financial accounting. Account. Organ. Soc. 12, 457-477. doi: 10.1016/0361-3682(87)90031-6

Knorr Cetina, K., and Preda, A. (2012). The Oxford Handbook of the Sociology of Finance. Oxford: Oxford University Press. doi: 10.1093/oxfordhb/9780199590162.001.0001

Krafel, P. (1999). Seeing Nature: Deliberate Encounters with the Visible World. Hartford, VT: Chelsea Green.

Lambek, M. (2013). The Value of (performative) Acts. HAU: J. Ethnographic Theor. 3, 141-160. doi: 10.14318/hau3.2.009

Lander, L., and Cooper, N. (2017). Promoting Public Deliberation in Low Trust Environments. Australian Use Cases. doi: 10.2139/ssrn.3077474

Latour, B. (1987). Science in Action. Cambridge, MA: Harvard University Press.

Lawrence, P. R., and Lorsch, J. W. (1967). Differentiation and integration in complex organizations. Adm. Sci. Q. 12, 1-47. doi: 10.2307/2391211

Lösch, A. (2006). Anticipating the Future of Nanotechnology: Some Thoughts on the Boundaries of Sociotechnological Visions. Department of Sociology, Technical University Darmstadt.

MacKenzie, D. (2009). Making things the same: gases, emission rights and the politics of carbon markets. Account. Organ. Soc. 34, 440-455. doi: 10.1016/j.aos.2008.02.004

Macpherson, C. B. (1973). Democratic Theory: Essays in Retrieval. London: Oxford Press.

Manski, S. G. (2017). Building the blockchain world: technological commonwealth or just more of the same? Strategic Change 26, 511-522. doi: 10.1002/jsc.2151

Manski, S. G., and Bauwens, M. (2020). Reimagining new socio-technical economics through the application of distributed ledger technologies. Front. Blockchain 2:29. doi: 10.3389/fbloc.2019.00029

Manski, S. G., and Manski, B. (2018). No gods, no masters, no coders? The future of sovereignty in a blockchain world. Law \& Critique 29, 151-162. doi: 10.1007/s10978-018-9225-z

Marx, K. (1993). Grundrisse. London: Penguin.

Marx, K. (2019). Capital: Volume One. Mineola, NY: Courier Dover Publications. McCarthy, M. (2018). Is Sociology Stuck in the Middle? The uses of Marxist General Theory. Marxist Sociology Blog. Available online at: https://marxistsociology. org/2018/10/is-sociology-stuck-in-the-middle- the- uses- of-marxist- generaltheory/ (accessed January 12, 2019).

Miller, P. (1990). On the interrelations between accounting and the state. Account. Organ. Soc. 15, 315-38. doi: 10.1016/0361-3682(90)90022-M

Mumford, L. (1966). Technics and the Nature of Man. Technol. Cult. 7, 303-317. doi: $10.2307 / 3101930$

Nakamoto, S. (2008). Bitcoin: A Peer-to-Peer Electronic Cash System. Available online at: https://bitcoin.org/en/bitcoin-paper (accessed January 12, 2019).

Ostrom, E. (1990). Governing the Commons: The Evolution of Institutions for Collective Action. Cambridge University Press.

Penow, C. (1986). Complex Organizations. New York, NY: Random House, third edition. 
Pryor, F. (1996). Economic Evolution and Structure: The Impact of Complexity of the US Economic System. Cambridge; New York, NY: Cambridge University Press.

Robson, K. (1992). Accounting numbers as 'inscription': action at distance and the development of accounting. Account. Organ. Soc. 17, 685-708. doi: 10.1016/0361-3682(92)90019-O

Roco, M. C., and Bainbridge, W.S. (2002). Converging Technologies for Improving Human Performance. Arlington, TX: Kluwer Academic. doi: 10.1007/978-94-017-0359-8

Rosser, J. (1999). On the complexities of complex economic dynamics. J. Econ. Perspect. 13, 169-192. doi: 10.1257/jep.13.4.169

Russell, J. (2018). Beyond Democracy: Increasing the Capacity, Context, and Combinatorial Possibilities. Medium.com. Available online at: https://medium. com/holochain/beyond-democracy-increasing-the-capacity-contextand-combinatorial-possibilities-7eebdd4ad079 (accessed December 27, 2018).

Selin, C. (2007). Expectations and the emergence of nanotechnology. Sci. Technol. Hum. Values 32, 196-220. doi: 10.1177/0162243906 296918
SENSORICA (2019). Homepage. Available online at: http://www.sensorica.co/ (accessed February 1, 2019).

Stavridis, J., and Weinstein, D. (2016). The internet of things is a cyberwar nightmare. Foreign Policy. 3.

The MetaCurrency Project. (2019). About - The MetaCurrency Project. Available online at: http://metacurrency.org/about/ (accessed February 1, 2019).

Tinker, T. (1985). Paper Prophets. New York, NY: Praeger Press.

Conflict of Interest: The author declares that the research was conducted in the absence of any commercial or financial relationships that could be construed as a potential conflict of interest.

Copyright (C) 2020 Manski. This is an open-access article distributed under the terms of the Creative Commons Attribution License (CC BY). The use, distribution or reproduction in other forums is permitted, provided the original author(s) and the copyright owner(s) are credited and that the original publication in this journal is cited, in accordance with accepted academic practice. No use, distribution or reproduction is permitted which does not comply with these terms. 


\section{APPENDIX 1}

\section{BLOCKCHAIN}

VER S U S

\section{HOLOCHAIN}

\section{COMPARING 2 DIFFERENT TECHNOLOGIES}

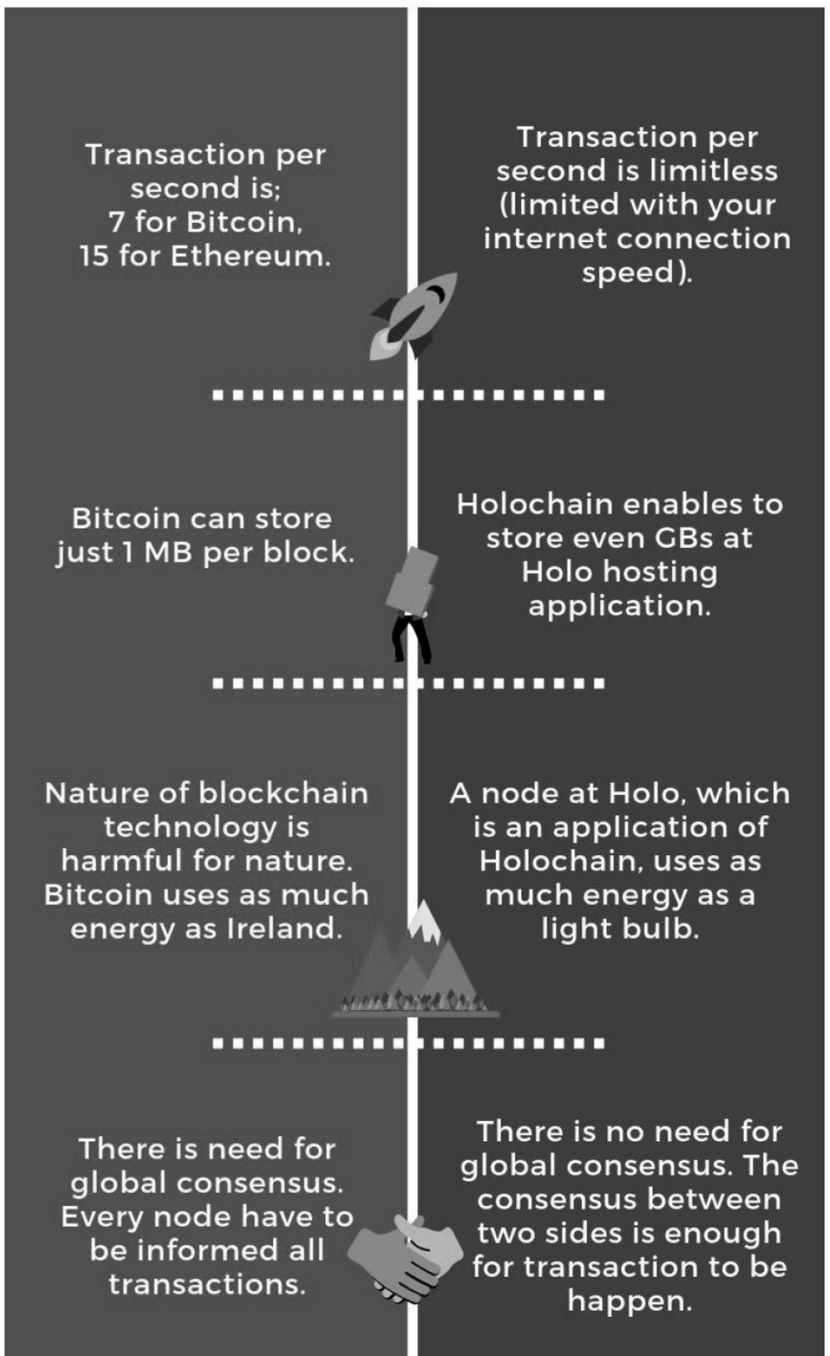

Blockchain versus Holochain (image used with permission. Created by Holochain).

\section{APPENDIX 2}

Agent Centric and Mutual Sovereignty Holochain Design Principles

- Anybody can try a new grammar (tweets, likes, rideshare requests, five-star ratings, etc.) without needing permission or support from others.

- Anyone that wants to communicate with them using that new grammar, can do so.

- If it proves useful, they can keep using it without requiring a business model that can extract value from the participants (they are using it due to intrinsic value).

- If it starts to prove too costly, annoying, or simply useless, they can alter in any way they see fit or abandon that grammar altogether.

- This enables far greater responsiveness by the participants in a community to the circumstances they face.

- Make it difficult for both corporations and states (powerful actors) from foreclosing possibilities.

- There are ecologically inspired patterns of organization that simply aren't possible with existing tools (http, dollars, incorporation, etc.). New tools like Holochain can enable coordination that is not dependent on access to or control over existing power structures (corporations, governments, etc.).

- It does not free people of the control that powerful entities might seek to wield. But it enables them to coordinate independently if they choose to. 